Acta Hispanica (2018) 23: 349-360

\title{
LA DANZA COMO CONSTRUCCIÓN DE NUEVOS HOGARES Y NUEVAS FRONTERAS
}

\author{
Ana Galina Giselle Paredes Padilla
}

Pontificia Universidad Católica del Perú

\begin{abstract}
Resumen: La inestable sociedad contemporánea, que incluye la complejización de tecnologías corporales, vulnera conceptos de hogar y frontera y es compatible con la subjetividad de migrantes, quienes lejos de los propios, apuestan por integrarse a otros horizontes culturales; para el efecto, comienzan con sus cuerpos y apariencias teniendo a la sofisticación de sus expresividades corporales como referentes estéticos de transformación. En esta ponencia ponemos en evidencia, a partir de dos historias de vida, cómo las tecnologías corporales propias de la danza, se convierten en mediadoras en la construcción de liderazgos locales y de ciudadanías alternas.
\end{abstract}

Palabras clave: migración, cuerpo, danza, capital erótico y coreografías vitales

\begin{abstract}
The unstable contemporary society, which includes the complexity of bodily technologies, infringes the concepts of home and border that is compatible with the subjectivity of migrants, who, far from their own, opt to integrate themselves into other cultural horizons; for this purpose, they begin with their bodies and appearances, taking into account the sophistication of their bodily expressivities as aesthetic referents of transformation. In this paper we show, from two life stories, how the body's own technologies of dance, become mediators in the construction of local leadership and alternate citizenships.
\end{abstract}

Keywords: migration, body, dance, erotic capital and vital choreography

En primer lugar, esta investigación etnográfica forma parte de la realización de un documental etnográfico de 30 minutos de duración, llamado Su Cuerpo, Su Capital ${ }^{1}$ cuya edición evidencia gran parte del trabajo de campo realizando a lo largo de dos años, indagando y penetrando en los espacios cotidianos y extracotidianos de dos estudiantes de danza clásica.

A partir de las historias de vida, Marco y Luis, dos jóvenes de entre 22 y 24 años, que habitan en los distritos de Carabayllo y San Juan de Lurigancho, respectivamente; ubicados a las afueras de Lima, capital de la República del Perú, los cuales se caracterizan por ser espacios inhóspitos donde se establecieron los

${ }^{1}$ Link del documental: https://www.youtube.com/watch?v=UxEopYu-1h4 
primeros migrantes provenientes de la sierra peruana y cuyos abuelos o padres pertenecieron a este grupo. Ellos son, por lo tanto, hijos o nietos de migrantes. Estos lugares los utilizan como espacios de reposo porque la mayor parte de tiempo se desplazan fuera de ellos, ya sea por sus estudios como por el trabajo; pero, también porque a pesar de que en estos espacios hay movimiento económico, recreativo y cultural; sin embargo, prefieren desplazarse por las calles del centro histórico de Lima, centro simbólico de poder y movimiento económico del estado nacional.

Ambos se forman en la Escuela Nacional de Ballet para ser intérprete y docente, respectivamente, además, están involucrados en una serie de actividades de desarrollo técnico del cuerpo que les permite actuar en diversidad de escenarios sociales en los que transmiten discursos heterogéneos, con los que se visibilizan y adquieren una notoriedad diferencial; por tal razón, esta investigación la propongo como una reflexión respecto al como las tecnologías corporales, propias de la danza, se convierten en mediadoras en la construcción de liderazgos locales y de ciudadanías alternas.

Es pertinente iniciar este artículo con la temática de las migraciones en el Perú, las cuales han ocurrido en diferentes épocas y, a veces, hasta por oleadas migratorias, que en conjunto han transformado el rostro de la capital y del país. Hasta antes de los cuarenta del siglo pasado, de los años cuarenta a los sesentas y la de los setentas. De los cuarenta hacia atrás es una migración de las élites, de las familias oligarcas que envían a sus hijos a estudiar en París, Londres; quiero decir que son migraciones de aquellas personas que poseen los recursos económicos para hacerlo; su ideal es que se van al extranjero a "blanquearse" más, socialmente hablando.

De los cuarenta a los sesentas se producen migraciones de las capas medias, no solo las elites, aquí ya participa un significativo grupo de la población de los Andes. Desborde popular como lo denominó José Matos Mar, reconocido estudioso de la sociedad peruana, en su investigación publicada y titulada Desborde Popular y Crisis del Estado que sirvió como referencia para gran parte para os científicos sociales de aquella época.

Dentro de este grupo de gente se encuentran aquellos que se escapan desde los 16 años de sus hogares para construirse un futuro mejor; en otros casos, como el de algunas mujeres que eran casadas, desde muy joven se escapan de sus casas y se 
dirigen a la costa como una forma de huir de los maltratos familiares; algunas veces llevan a sus hijos, otras no. Ejemplos visibles de este fenómeno son: Pastorita huaracina empleada del hogar, y luego convertida en una famosa cantante vernacular, Picaflor de los andes que se dedica a ser camionero, entre otros.

La mayor parte de estos migrantes sobreviven en la capital desarrollándose como empleadas domésticas, en el caso de las mujeres, y en el desarrollo de actividades de servicios o en el comercio ambulatorio, en el caso de los hombres; así, se dedican a labores de mecánicos, estibadoras, cargadores, conductores camioneros.

En los setentas los migrantes son familias enteras, es la época de las migraciones masivas. Este fenómeno transforma el rostro de las ciudades y del país y, de lo antes fue claramente rural se convirtió en estrictamente urbano, ahora las tres cuartas partes de la población viven en las ciudades y un cuarto en el campo. Esta población, al no encontrar lugares de trabajo, se dedicaron a crear el propio y lo hicieron apropiándose de las calles como vendedores ambulantes, son gente que trabaja en lo que se les presente y les dedican a estas actividades el doble del tiempo que le dedican en el trabajo formal y no hay días de descanso ni fines de semana, es formidable su empeño al trabajo y es, probablemente, una condición de su tradición histórica y cultural.

Dentro de lo que ha ocurrido en los espacios urbanos, progresivamente, se han consolidado nuevas formas de relaciones económicas y, a la larga, han emergido como un nuevo sector económico vinculado al comercio; hoy, es el sector económico que tiene más ingresos líquidos comparados del país. A este sector pertenecen las familias de mis sujetos de investigación, los abuelos de padre de Marco son de Canta, una provincia de la sierra de Lima, y su abuela materna es de Cerro de Pasco. Tanto su padre como su mamá terminaron la secundaria y se dedicaron a diversos oficios. Es decir, no tuvieron las posibilidades de acceder a una educación superior, como si lo han obtenido para sus hijos.

Su padre, es operador de maquinaria en una imprenta, desde joven empíricamente aprendió del negocio para; luego, invertir su capital en maquinaria y convertirse en propietario de su propia imprenta familiar; donde, la mamá de Marco y sus hermanos, han sido instruidos para que ayuden en el negocio familiar. Marco participa activamente llevando encargos y compaginando o engomando. En cambio, su madre salió del colegio y estudio cosmetología para, luego, llevó cursos de 
redacción ejecutiva. Ahora está separada del padre de Marco y trabaja como administrativa de una fábrica de empaques de una marca reconocida.

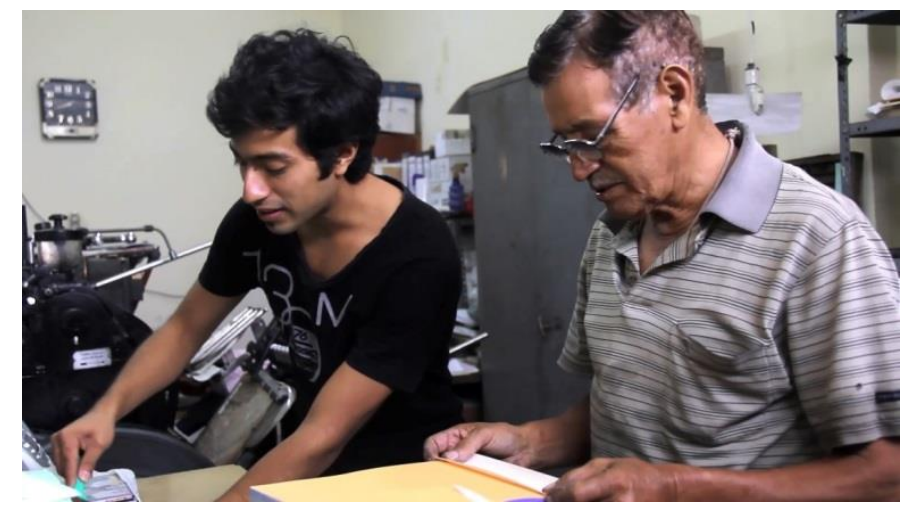

En el caso de Luis ambos padres son migraron, su padre es de un pueblo de Arequipa (región del sur del país) llamado Zaina y su madre de Cajamarca (región al norte del país), específicamente de Cajabamba. Su madre se desempeñó como trabajadora del hogar, desde adolescente, y su papá trabajó en diferentes oficios técnicos, sobre todo, después de acabar la secundaria en el caso de su padre mientras su mamá llegó a estudiar hasta el nivel primario. Ahora poseen un hogar propio que van construyendo piso a piso hacia arriba y alquilan la cochera a una señora para una bodega. Así viven de sus rentas, más el trabajo de su padre. Además, los tres pisos de la casa de Luis funcionan como cuartos donde suelen hospedar a sus primos y tío de provincia quienes lo visitan esporádicamente.

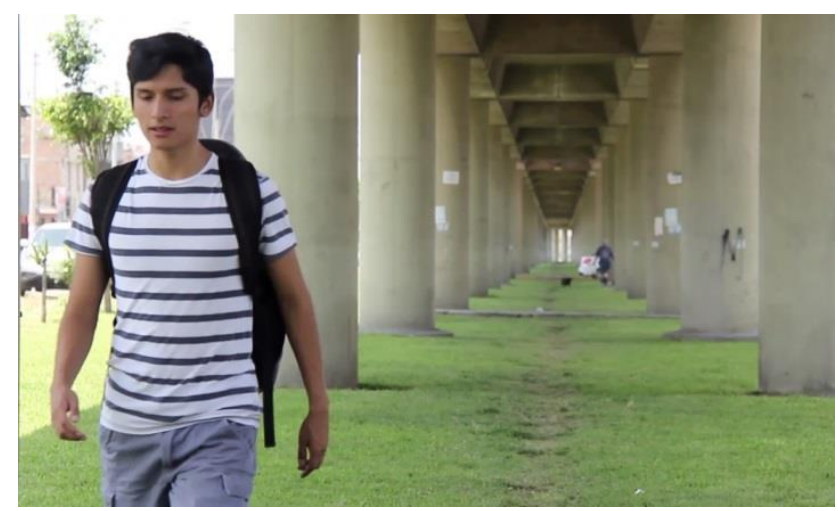


En este sentido se evidencia la forma en como sus abuelos, y luego sus padres, reproducen en la ciudad el capital cultural que lograron en sus relaciones comunales, en sus lugares de origen. Su predisposición a variar sus coordenadas culturales de referencia por las nuevas adquiridas es un factor que se traslada a la constitución de sus empresas familiares que son muy flexibles y adaptables a las demandas del mercado. Algo importante a destacar es que si bien, en ambos casos, sus padres no tuvieron educación superior, éstos han invertido en carreras universitarias para sus hijos, tal vez pensando en carreras más funcionales a sus negocios familiares.

Marco optó por la publicidad como carrera universitaria aunque, según me confesó, hubiera querido dedicarse profesionalmente al arte; pero, sus padres no se lo permitieron y a larga se ha dado cuenta que no fue mala elección dicha formación profesional; ya que, en estos últimos años había advertido que era una carrera muy holística; mientras, Luis decidió estudiar lingüística, en la Universidad Nacional Mayor de San Marcos, porque se sentía atraído por las letras y más tarde por la danza disciplina corporal posee una estructura o sistema de pasos a decodificar como el lenguaje.

El contraste se evidencia en que la universidad que eligió Marco responde a las denominadas universidad empresas, las cuales e centran básicamente en formar productiva y eficazmente a sus egresados cuyas carreras sean funcionales en el mercado laboral. Y en caso de la universidad de San Marcos responde a universidad nacional de gran prestigio, pero cuya formación es humanista y donde el activismo político nace en las aulas de dicha institución educativa.

Pues la danza y diversas tecnologías corporales fueron integrándose en los intereses de Luis y Marco en diferentes etapas de tu vida. Marco relata que su madre siempre lo impulsó a realizar deportes, que cuando tenía siete años practicó Marinera, danza nacional del Perú, que el profesor le recomendó a su madre que lo llevara a la escuela nacional de ballet al ver sus condiciones; opción que fue desechada por su madre porque, según ella, eran cosas de niñas. Luego, a los nueve años practicó karate, a los diez, taekwondo, a los catorce kickboxing.

La elección por estas disciplinas corporales de defensa personal respondían a un tipo de protección en la escuela donde era bullyeado como gay, además, porque quería diferenciarse ya que solía ser un nerd o ratón de biblioteca; pero, a los 15 años ya estaba muy interesado en el ballet y, por su iniciativa, había averiguado 
sobre los lugares de enseñanza; así que, con las propinas que le daban sus padres, los fines de semana comenzó a asistir a la Casona de San Marcos ${ }^{2}$, donde él era el único varón, y comenzó desde cero a estudiar ballet; luego, se formó en una escuela en el centro de Lima que pulía la técnica, sobre todo de los varones, quienes empezaban muy tarde y ya tenía en mente postular el año siguiente a la escuela nacional superior de ballet para lograr una formación profesional.

Luis Ángel, por su parte, ya había egresado de su carrera universitaria y había probado desde el colegio en talleres de bailes afroperuanos, hip-hop, danza contemporánea, teatro e integrando elencos donde representaba coreografías ante diversos públicos y contextos. Finalmente llegó la curiosidad por experimentar en/desde su cuerpo el ballet, también en la misma escuela de ballet donde asistía Marco, en el centro de Lima. Según él siempre tuvo la inclinación por esta danza aún cuando, dentro de su entorno familiar, parecía muy lejano o extraño, él mismo se preguntaba en qué momento le comenzó a gustar el ballet. Recuerda que un amigo le indicó que en la Escuela Nacional Superior de ballet estaban demandando bailarines varones para formarlos y que les daban becas. Se preparó e ingresó para la carrera universitaria de docente en danza clásica, la cual acabó el 2017. Esta información concuerda con la que dispongo ya que, en la época del 2010, cuando asistía como alumna libre a la escuela y que fue el origen de mi interés por esta investigación, había una gran población de alumnos varones formándose en ballet, profesionalmente, lo cual era extraño en una sociedad tan conservadora y pacata como la limeña.

\footnotetext{
${ }^{2}$ Espacio que pertenece a la Universidad Nacional Mayor de San Marcos donde ubicado en el centro histórico de Lima donde se imparten talleres de danza clásica y contemporánea entre otras expresiones vinculadas con el arte y las humanidades funcionando a modo de centro cultural, en cuyas aulas se han formado y han egresado muchas generaciones de bailarines incluso antes de existir forlmalmente la Escuela Nacional de Ballet del Perú y donde han dado cátedra grandes estrellas internacionales del mundo de la danza.
} 


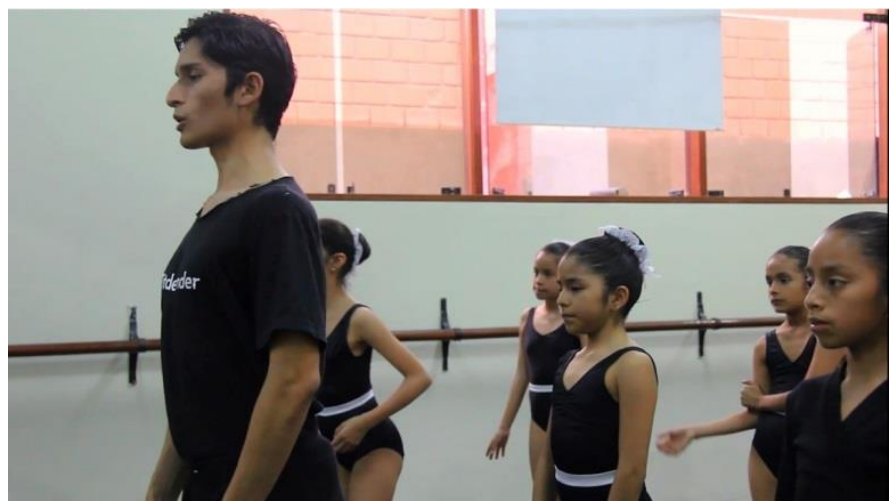

Me enteré que se les ofrecía becas y que les cobraban menos que a las chicas; los que respondieron a la convocatoria eran, en su mayoría, de los conos de la ciudad o de provincias. Muchos de ellos sin una base en ballet o danza y otros practicaban danzas urbanas o contemporáneas; pero, de formación empírica en talleres varios. $\mathrm{Y}$ algo que quedaba claro era que muchos de ellos escogían la danza clásica solo como un medio para formarse y estilizar sus movimientos y posturas; pero, luego desertaban para formar sus propias empresas dancísticas, en las que confluían diversidad de tecnologías corporales que eran comerciales y servían para ese fin.

Esto no se aleja mucho de los intereses de nuestros protagonistas quienes también ingresaron con una idea de ballet, pero en el camino, fueron consciente que su biotipo no encajaba con el de primer bailarín y no es algo que los haya frenado; al contrario, deciden apropiarse de esta técnica hegemónica porque en ella siguen rigiendo cánones de belleza y estilización de cuerpo que responden a un tipo especial del mercado laboral.

Es en el espacio de formación institucionalizada en la escuela que comienzan a descubrir un mundo muy diverso, en cuanto a orientación sexual de los estudiantes, y respecto a la valoración del cuerpo en otro tipo de espacios. En primer lugar, comienzan a cambiar sus rutinas corporales y alimenticias compartiendo consejos sobre qué comer y qué no. Así como que estiramientos realizar y con cuánta intensidad, lo que, a las finales se convierte en una rutina diaria y para siempre, como un conocimiento incorporado o añadido a las coreografías cotidianas que ambos performan en distintos espacios familiares. 


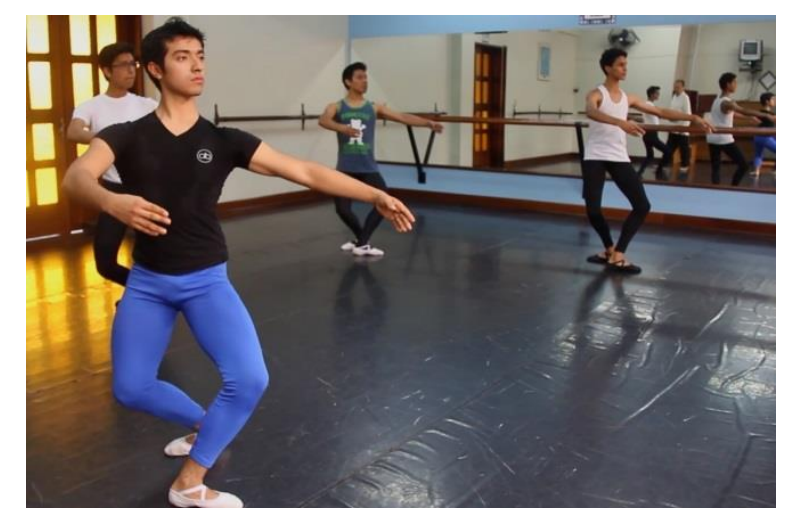

Tanto para Marco como para Luis constituye espacios donde van a interactuar y conocer otro tipo de acercamientos y propuestas desde lo corpóreo; así, como en el caso de Luis se sienten más empoderados de reafirmar su orientación sexual y acercarse más a un tipo de activismo sobre los derechos LGTBI+ Q, a través de la expresión misma del cuerpo o, en el caso de Marco, que le sirve para cuestionarse sobre la misma y sobre sus gustos los cuales, en el espacio del colegio o en su entorno familiar, habían sido sublimizadas o reprimidas.

El ámbito de la danza representó, para ellos, un espacio liberado de estereotipos y, sobre todo, de transgresión; pero, sobre todo de propuesta. Si bien en la escuela el rol que ellos juegan es el del receptor alumno, eso no quita que su capital cultural incorporado active cierta vehemencia transmitida por sus abuelos y padres en el sentido de desafiar lo establecido para reconfigurarlo, en algo nuevo o híbrido. Me refiero a la herencia inherente que cargan consigo los cuerpos de los migrantes que suelen transformar el espacio y adecuarlo a sus necesidades y posibilidades

La diferencia es que ellos no han sido alentados por sus familias, para experimentar, en estos otros ámbitos de desarrollo y movilización social, que parten desde el cuerpo y la formación artística, sino, que se han originado desde sus exploraciones e intereses que han ido sido, cada vez más sofisticados, en cuanto a su preparación corporal. Es por eso que ambos, paralelo a su formación en la escuela, no han dejado de experimentar desde sus cuerpos diversas tecnologías corporales que han creído necesarias para extraer otras posibilidades de movimiento y agregarlas a su saber corporal y, por tanto, pensando en un futuro, puedan insertarse en diversos campos laborales que la danza demanda y en una multiplicidad de saberes y tecnologías corporales para poder copar ciertos mercados comerciales. 
Por ejemplo, Marco comenzó a llevar talleres de stretching, preparación física para mejorar su condición corporal y, luego, probar acrobacia; en este tiempo ya había abandonado la escuela; en cambio, Luis siguió graduarse como docente, ha participado en presentaciones formales y de repertorios clásicos dentro de la escuela; pero, paralelo ha formado parte de puestas en escena de otro tipo de eventos en instituciones formales e informales; así como, ha estado muy comprometido con una ONG que buscaba compartir, desde el cuerpo y el movimiento, con personas con discapacidad.

De esta forma es que ambos estuvieron participando en roles principales, en puestas en escenas, de coreógrafos independientes; quienes los convocaban y aceptaban, muchas veces, sin pago alguno; tan sólo por el hecho de ir adelantándose y experimentando ese trabajo como director bailarín; algo que se daba en la escuela, donde ellos solo formaban parte de su cuerpo de baile. En el caso de Marco también participó de un evento comercial en una fiesta de halloween donde necesitaban acróbatas, la última tecnología corporal que estaba experimentando, luego, de dejar la escuela. Este si fue remunerado e interactuó con muchos jóvenes de su edad y mayores que se dedicaban al medio circense; mundo, al cual, miró con ilusión y esperanza de algún día pertenecer desde que observó una puesta del Cirque du Soleil.
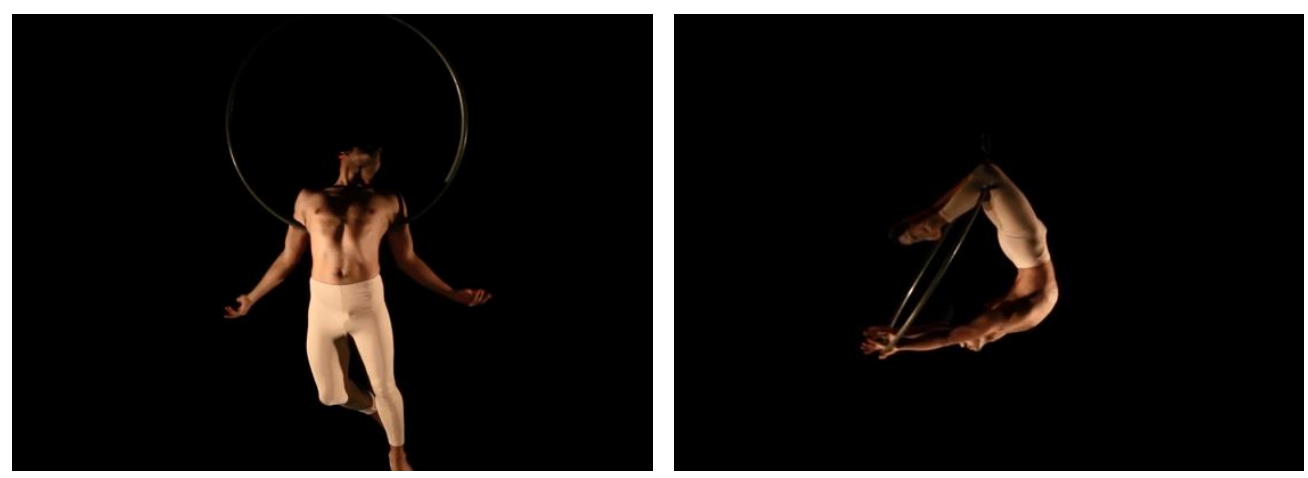

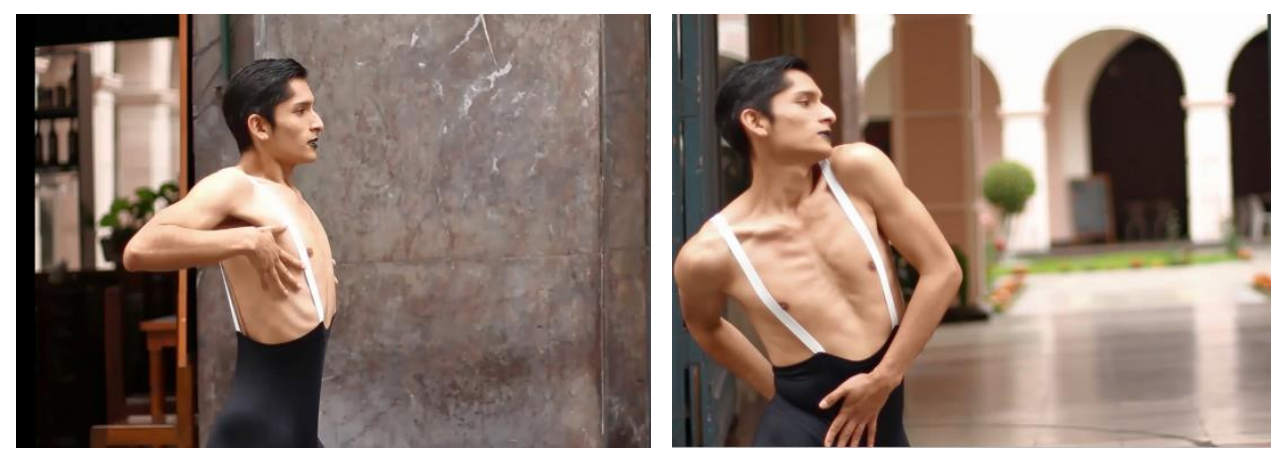

Es cierto que ambos van incorporando a su capital cultural otros capitales (Bourdieu, 2000) y en diversas composiciones; pero, hay uno más de vital importancia, me refiero al capital erótico, que fue propuesto por Hakim (2012); en su tesis él lo conecta con otras dimensiones del uso del cuerpo como capital. Es decir, no es que estén manipulando sus cuerpos con diversas disciplinas corporales sino que, a través de la potencialización de su capital erótico, puedan acceder a otros espacios sociales donde el erotismo juega un rol importante; por ejemplo, Marco es consciente de que su cuerpo es como su carta de presentación no solo a nivel performático, en las calles o en puestas en escenas donde se presenta, sino también en espacios como grinder, una app internacional de sexo casual donde tener un cuerpo atlético, joven y sano, importa demasiado para tener la mayor cantidad de parejas sexuales.

Luis también refiere lo mismo dentro de sus conversaciones con amigos respecto al sexo, considera que no es muy importante tener una cara hermosa, pero si un cuerpo agradable de tocar. Por tal razón, la capitalización de sus cuerpos tiene varias fuentes, la principal de ellas -o fuente base- lo constituyen sus actividades cotidianas, aquellas en las que participan con su entorno familiar, me refiero a su imprenta, a las que desarrollan en las múltiples escenas en el hogar, a las que se generan en sus desplazamientos por diferentes escenarios sociales; a todas estas formas que V. Fuenmayor (2004) denomina ritmos sociales que se encuentran ausentes en la reflexión académica cuando define muchas de sus conductas y de sus actos y cumple un rol determinante en la construcción de los cuerpos danzantes.

La segunda fuente lo constituye la formación institucional, aquella en la que procuran una formación profesional en danza y que bajo un proceso fino se logra la transformación de un cuerpo cotidiano en otro artístico. Por lo menos, eso es lo que dicen los perfiles profesionales de quienes hacen la convocatoria; sin em- 
bargo, hay estereotipos de bailarines óptimos que nuestros entrevistados no cumplen, como la mayoría de quienes postulan a estas instituciones, ni existen los necesarios puestos de trabajo para sus egresados; entonces, la institución -al cual lo afirma su directora en entrevista- y sus estudiantes varones se preparan para obtener una base técnica para su cuerpos para performar frente a públicos diferentes a los previstos y que, por azahares del destino, es la mayoría de la población de la capital de la República del Perú.

La agencia de cuerpos con mayor plasticidad, evidentemente, lo logran en estas rutinas diarias y; un cuerpo, de esta naturaleza, ya constituye o está sumergido en un proceso de erotización, que suma en su conversión en capital.

La tercera fuente lo constituye la formación técnico corporal no institucionalizada, aquella que Marco y Luis se agencian intencionalmente o porque se cruzaron en su recorrido y consideraron que suma en su formación, que les proporciona elementos para formarse y para explorar otros mercados de consumo, además, de involucrarse en procesos de gestión debido a que, en estas experiencias, los responsables generan el producto y, simultáneamente, lo colocan en mercados ambulantes.

Es notorio que la ciudad, culturalmente heterogénea, hace posible que estos proyectos se concreten. La cercanía con los públicos variados los insertan en un cúmulo de emociones y de experiencias (Briceño, 2011) que van definiendo formas eficientes de comunicación directa con la población y comprensión para el establecimiento de comunicaciones intersubjetivas que, a la postre, van perfilando las características necesarias para convertirlos en actores sociales, en la medida en que reconocen las aspiraciones de la población, que las saben interpretar y que les devuelven en códigos estéticos decodificables o comprensibles para sus consumidores.

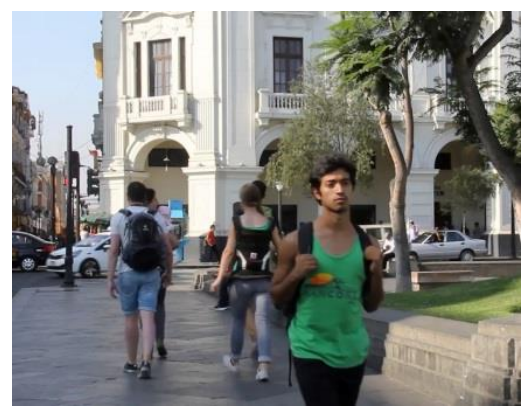


A esto se conjuga la construcción de liderazgos nuevos; ya estabilizados, conocen las relaciones que se producen en los espacios urbanos porque se han socializado dentro de estos contextos y buscan auto-representarse, conocen y manejan los sentidos sociales propios de la ciudad. Conociendo esas reglas ya no esperan que otros los representen. Sino que ellos construyen sus propios liderazgos y así aparecen estas dos historias de vida, a las que he explorado en/desde sus propios cuerpos los capitalizan y lo convierten en personajes públicos porque actúan como actores sociales y tienen, a su propio cuerpo, como espacio de experimentación de tecnologías corporales diversas con las cuales actúan frente a la heterogeneidad social.

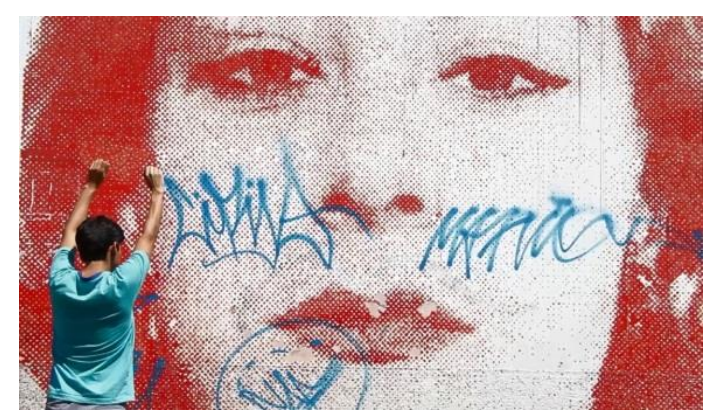

\section{Bibliografía}

Bourdieu. 2000. "Las formas del capital. Capital económico, capital cultural y capital social" Poder, derecho y clases sociales. Bilbao: Desclée de Brouwer. 131-164. Briceño, Gloria. 2011. "El cuerpo como performance en la sociedad del espectáculo" Estudios sobre las Culturas Contemporáneas, II/XVII/ 34. 9-30.

Fuenmayor, Víctor. 2004. "Técnicas del cuerpo y técnicas de la danza" La otra facultad, I/1. Universidad del Zulia: Facultad Experimental de Arte.

Hakim, C. 2012. Capital erótico. El poder de fascinar a los demás. Barcelona: Debate. 